\title{
Modelling the relationships between factors affecting the marketing of upgrades for personal computer
}

\author{
L. McCarney* \\ Graduate School of Business, University of Durban-Westville, Private Bag X54001, Durban, 4000 Republic of South Africa \\ D. Petkov \\ Computer Science and Information Systems, University of Natal, Private Bag X01, Pietermaritzburg, 3209 Republic of South Africa \\ R. Ross \\ ICL, P.O. Box 1069, Pietermaritzburg, 3200 Republic of South Africa
}

Received October 1996

\begin{abstract}
The purpose of this research is to provide a framework for prioritizing the factors that affect whether or not personal computers (PCs) are upgraded. The implications of this may influence product development, manufacturing and marketing. The model presented in this article is an extension of an idea by Lambkin \& Day for a holistic treatment of the forces affecting marketing to the case of upgrades for PCs. The authors have used the Analytic Hierarchy Process (AHP) as a technique that permits the introduction of structure into this complex problem thus helping managers of vendor companies marketing upgrades to PCs to devise strategies for effective marketing.
\end{abstract}

Keywords: product life cycle, personal computers' upgradability, marketing, AHP

*Author to whom correspondence should be addressed.

\section{Introduction}

The importance of the market for sales of upgrades of personal computers (PCs) and the extension of their useful life is exemplified by the enormous customer base for these products. The PC industry, since the early days of the IBM Personal Computer, more than a decade ago, responded with an incredible flood of upgrade products (Seymour, 1992). Due to the modularity of personal computers and the promotion of certain standardized computer architectures by a wide range of manufacturers, upgrading is an essential and effective way for product innovation to take place. Typical methods of increasing the performance of the microcomputer include installing more memory or a larger hard disk, speeding up video performance, or installing a new, faster central processor unit chip (Seymour, 1992).

The purpose of this research is to assist in providing a framework for prioritizing the factors which affect whether or not PCs are upgraded. The implications of this influence product development, manufacturing and marketing. The importance of an integrated treatment of the three areas is obvious (see Karmarkar, 1996), but for practical reasons this study was limited to the marketing side of the problem. This may, according to Bretschneider \& Wittmer (1993), be justified also on the basis of the importance of the market as an environmental factor affecting organizational adoption of microcomputers which itself is a prerequisite for the demand for PC upgrades.

The issue of increasing the sales of PC upgrades can be classified as a complex marketing problem, following the general criteria outlined in Dyer \& Forman (1991). It incorporates knowledge about qualitative and quantitative variables that are affected by more than one goal, as is demonstrated later in this article. From management's perspective it would be useful to find a way to rank those factors related to the successful marketing of PC upgrades so that computer vendors can concentrate on those that appear most important and thus determine the most effective marketing strategy.

It is interesting to look at the process of upgrading personal computers from the point of view of the product life cycle (PLC) theory. Applying Kotler's approach with reference to the PICC the products of the computer industry may be classified as product categories (or classes as they are referred to by Lambkin \& Day, 1989), while personal computers may be classified as product forms (Kotler, 1988). Although a full exploration of the PLC phenomena, and brand extension in particular related to the computer industry, falls outside the scope of this study it is worth mentioning that some useful recent work on this interesting topic for similar types of industries has been done (Sridhar Moorthy \& Png, 1992; Sullivan, 1992). The focus of this study is confined to considering microcomputers as a product form, since research indicates that the latter tend to exhibit the standard PLC histories more faithfully than do product categories (Kotler, 1988).

The question then arises as to which stage of its development according to traditional PLC theory is the microcomputer industry in. In taking Seymour's (1992) findings as a guide, it would appear that today, a very significant part of the PC business has become a replacement business, leading one to the conclusion that personal computers are in their growth/ maturity stages as products. It is a world-wide trend that the sales of PCs continue to increase or, in some short periods, there is a relatively insignificant slowdown when compared with the decrease in the past five years of sales of mainframes and minicomputers, affecting the biggest computer companies like IBM and Digital Equipment Corporation. Among the many strategies that may be used by the firm to sustain market growth in such an environment are the addition of 'flanker' products and the exploitation of niche markets (for additional discussion, see Aaker, 1990). The provision of upgrades is a relatively easy way to achieve these strategies. Historically such upgrades evolved with the appearance on 
the market of new generations of computer chips or, as some authors claim, these are sequential introductions of innovations of brands and products dictated by exogenous technological improvements (Sridhar Moorthy \& Png, 1992).

According to Lambkin \& Day (1989), the forces affecting PLC usually fit into three categories: the demand system, the supply system and industry factors. The model presented in this article is an extension of the idea by Lambkin \& Day for treating these forces as an integrated whole. The authors have used the Analytic Hierarchy Process (AHP) as a modelling tool, permitting the introduction of structure into the problem. The contribution of this article is to suggest a way for formal structuring of the problem and the measuring of the influence of the factors affecting marketing of upgrades for PCs on the sales of such products. The results presented in the third section of the article refer to the application of the suggested model to the marketing of upgrades for PCs facing a local subsidiary of a large international computer company. It should be noted that the numerical values of the comparisons in this model, as well as the results, are provided for illustrative purposes where the portability of the model is concerned. Obviously. in other environments these may vary. In support of this contention one may point out that King et al. note that not all institutions are equally adept at facilitating IT innovation and the mix of adept institutions will vary from place to place (King et al., 1994). Discussing the issues related to the international generalizability of management science research for social systems, Rosenzweig concludes that they consist of variables, the relationships among which often differ from country to country (Rosenzweig, 1994). However, it may be argued that the proposed AHP model provides a framework for handling such managerial problems and in particular circumstances, the model structure can be modified slightly and the comparisons may be different to reflect the actual constraints on the decision-making process in that environment.

The Analytic Hierarchy Process was developed in the seventies by Saaty. The first application of this technique to marketing was reported in 1980 (see Wind \& Saaty, 1980). Dyer \& Forman (1991) have shown a number of other possible applications of AHP in the same area. Commenting on the possible use of judgemental modelling techniques in marketing, Naudé \& Locket (1993) consider Saaty's method to be one of the more comprehensive approaches. Schoemaker \& Waid (1982) experimentally compared five technologies for determining weights in additive utility models and found that AHP was superior to the rest. A wide set of applications in different areas are discussed in Saaty (1990). A review of software packages supporting decision making with the Analytic Hierarchy Process and some other techniques is presented in Buede (1993). Regarding the publicized debate related to the possibility of rank reversal in AHP under special circumstances, the authors support the treatment of this issue contained in Saaty's latest book, where it is pointed out that a conclusion on these aspects of AHP depends heavily on the initial assumptions within a particular problem situation. Sufficient support for the validity and applicability of AHP as a modelling approach is provided in the papers included as an appendix of Saaty (1990) and in the bibliography on AHP (Saaty, 1994). Regarding the issues discussed in this article it would appear from an extensive literature search that applica- tions of the Analytic Hierarchy Process to this problem axe not reported. There is also no significant evidence of which the authors are aware that marketing research has as you de. veloped a more efficacious technique for handling this issue of high technology markets. As Heide \& Weiss (1995) sug. gest, the problems that exist in such markets are related to the uncertainty of the market due to the rapid changes in it. This article attempts to present an analytic framework that helps to improve the understanding of the factors affecting the market ing of upgrades for PCs from the vendor's point of view and thus to decrease the above uncertainty, hopefully leading to improved management insights.

Prior to the building of the AHP model described here some basic data was generated from the informed experience of 16 opinion leaders in the field of marketing and purchasing of PCs for industrial and commercial use. Due to the small size of the sample the findings could not, in themselves. be treated in a strict statistical fashion but rather they served as a preliminary indication regarding the relevance of the factors. Most of the fact-finding procedures involved interviews and discussions with the experts involved. These exploratory findings were combined during the process of deriving the factors affecting the marketing of upgrades for PCs and building the model with ideas from sources on software and hardware selection such as Rosenthal \& Salzman (1990) and with the 27 years of expertise of two of the authors with the product form. As Saaty points out, to construct a hierarchy one needs creative thinking, recollection, association, memory, other peoples perspectives, and one also needs to learn in the process of construction (1994). For more guidelines on the problem definition in AHP and relevant examples the reader is referred to the same source.

The remainder of the article is organized as follows: the second section discusses the structure of the proposed model, and the third section presents the research findings which are followed by the conclusion. The appendix provides some background on AHP, making the assumption that the reader has some knowledge of this modelling approach.

\section{Structure of the proposed model for the prioritiza- tion of factors affecting the marketing of upgrades for personal computers}

The hierarchy of factors affecting the sales of upgrades to personal computers is presented in Figure 1. At the first level is the overall goal: to increase the sales of upgrades for PCs. At the second level are the subcriteria:

- Better understanding of the target market, or the demand system for upgrades to PCs.

- Higher customer satisfaction through improved supplier performance.

- Additional features affecting the upgradability of the existing PC equipment of the customer base.

It should be noted that there are similarities between these subcriteria and the ones used by Lambkin \& Day (1989), although their paper attempts to reveal the more general framework for understanding market evolution through the product life cycle on the basis of product class or category. Since this model is dealing with a product form such as microcomputers, the factors affecting the subcriteria in the proposed model are more specific and their number is reducer when comnared to 

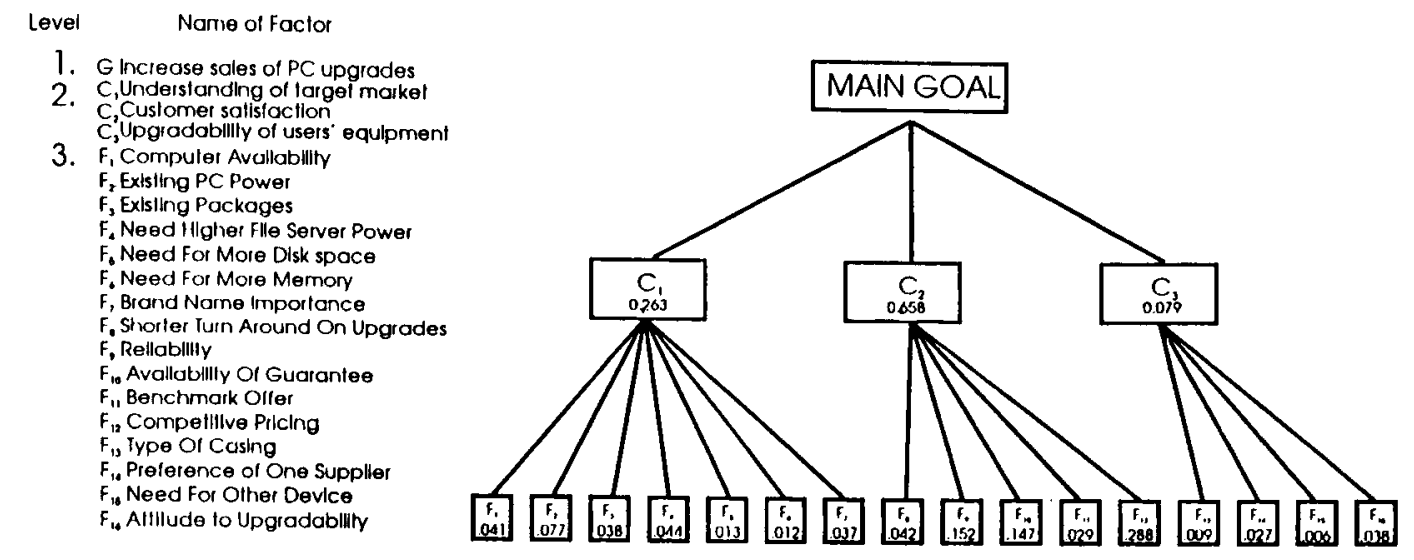

NB: The numbers beneath a factor show its global priority with respect to the overall goal increase of the sales of PC upgrades.

Figure 1 An analyctic hierarchy model of the factors affecting the marketing of upgrades to personal computer

those used in Lambkin \& Day (1989). The latter model attempts to include all possible factors applying to any product class but some of them are not applicable to product forms and to microcomputers in particular.

The subcriteria are effected by the factors at the third level of the analytic hierarchy as follows.

Factors affecting the first subcriterion regarding the features of the target market

- Computer availability or density of saturation of the market which corresponds to the current level of investment in microcomputers within the customer base;

- Existing PC power at the disposition of the customers reflected in the predominant model of microprocessors that is prevailing;

- Existing software packages in possession of users;

- The need for higher file server power to handle increasing user requirements in the shift to networking of PCs;

- The need for more disk space as a result of the requirements of new releases of software applications;

- The need for more primary memory in PCs; and

- Importance of the brand name reflected in the preferences of customers.

Factors affecting the second subcriterion regarding the improvement of customer satisfaction through better supplier performance

- Shorter turn-around time of upgrades, or the time from the placing of an order by a customer to its realization;

- Reliability of the service provided by dealers;

- Availability of guarantees offered by dealers;

- Dealer offer of a benchmark test on the equipment; and

- Competitive pricing.

Factors affecting the third subcriterion, representing some additional considerations affecting the upgradability of the existing PC equipment at the disposition of the customer base

- Type of casing for microcomputers that is currently popular;

- The typical preference of sole supplier by customers;
- The need on the side of dealers to provide for other devices, generating more need for PCs upgrades; and

- The computer industry's attitude towards upgradability.

These lists include the most significant factors (in the authors' opinion) which affect the subcriteria of the problem under consideration. It is possible, if necessary, to include further factors that have been found to affect microcomputer adoption in a given client organization like the tasks performed within the customer base, organizational size and user experience with computer technology thus reflecting the circumstances in a specific environment. The next section provides a discussion on the results from the use of the model for the case under consideration in this study.

\section{Interpretation of the results from the model}

The next step in building the model is to provide pairwise comparisons between each two elements in the hierarchy with respect to the root of the cluster to which they belong. Thus as a result of the pairwise comparisons between the subcriteria from the second level with respect to the main goal given the characteristics of the operating environment of the computer company under consideration, the highest priority is obtained for customer satisfaction through improved supplier performance, followed by a better understanding of the promotional target market and the additional upgradability features (see Table 1). Note that the local priorities reflect the importance

Table 1 Comparisons of the subcriteria with respect to the overall goal: increase of sales of upgrades to personal computers

\begin{tabular}{lccc}
\hline Subcriteria & 1 & 2 & 3 \\
\hline $\begin{array}{l}\text { 1. Understanding of target market } \\
\begin{array}{l}\text { 2. Increased customer satisfaction through better sup- } \\
\text { plier performance }\end{array}\end{array}$ & 3 & 2 & 7 \\
$\begin{array}{l}\text { 3. Additional features affecting upgradability of PCs } \\
\text { Ad/4 }\end{array}$ & $1 / 7$ & 1 \\
\hline
\end{tabular}

NB: The comparisons in each cell were obtained as an answer to the question 'How does the importance of subcriterion A compare to that of subcriterion B with respect to the overall goal' using the following 19 scale: $I=$ equally, $3=$ moderately, $5=$ strongly, $7=$ very strongly and $9=$ absolutely more important. The other values are intermediate. If the second subcriterion is more important than the first then the value is reciprocal. 
of elements with respect to the root of a particular cluster while the global priorities represent the weight of the alternative with respect to the overall goal, taking into account all subcriteria. Both are equal only for the second level for obvious reasons.

The comparisons at lower levels of the hierarchy are not shown for space reasons. The calculated local and global priorities of the factors from the third level are presented in Figure 2. It shows also which factors affect a particular subcriterion. The highest local priorities with respect to the first subcriterion (better understanding of the target market) are obtained for existing PC power, followed by the need for higher file server power and computer availability. This demonstrates the need to know not just generally that a customer has some PCs, but also to be informed about the microprocessor type and power of their PCs as a potential market for upgrade devices.

The highest importance with respect to higher customer's satisfaction through improved vendor performance is obtained for competitive pricing, followed by reliability of service and availability of a guarantee for the product. On the other hand the lowest priority is for an offer of a benchmark test for a particular type of computer equipment. This however does not invalidate the usefulness of such tests.

With respect to the last subcriterion, additional upgradability features, the most important turned out to be the computer industry attitude to upgradability, followed by the customer preference for one supplier, while two technical factors, the type of microcomputer casing and need for other devices supporting upgradability of PCs received lower priorities. This demonstrates the prime role of psychological factors in the model under discussion.

The analysis of the global priorities of the factors from the third level shows that the most significant factor was determined as competitive pricing $(0.288)$, followed by reliability of service (0.152), availability of a guarantee (0.147) and existing PC power within the customer base $(0.077)$. This result is in line with the findings of Gurbaxani \& Mendelson who stress the effect of the price trend on Information Systems spending in addition to the role of innovation diffusion (Gurbaxani \& Mendelson, 1994).

On the basis of their global priorities least important are the need for other devices, supporting upgradability of $\mathrm{PCs}$ (0.005), the type of microcomputer casing (0.009), the need for more memory $(0.012)$ and the need for more hard disc space (0.013). The latter factors are of technical nature and their low priorities reflect the unification in the area of casing for PCs and the relatively low prices of memory and disks.

It is recognized, as hinted earlier, that under different conditions some variations in the comparisons and in the priorities of the factors are possible. Depending on the type of customer base, one may include in the model other factors as discussed in some models explaining information technology innovation (e.g. Boynton et al., 1993; Bretschneider \& Wittmer, 1993 and King et al., 1994). The comparisons supplied for this model reflect partially the information gathered through interview, discussions and an administered auxiliary questionnaire survey of 16 corporate customers for PC upgrades within the area of activity of the considered computer company and, on the other hand, the practical and academic experience of the authors. The Analytic Hierarchy Process is also a systemic theory of measurement and as such it allows the incorporation of a broad range of qualitative and quantitative data in the model from various sources. It is important to point out that the model in itself was formulated from the point of view of and for the real purposes of a particular vendor company to which one of the authors belonged. The exploratory preliminary questionnaire and interviews with the 16 potential clients provided customer input on various issues related to $\mathrm{PC}$ upgrades and contributed to the formulation of the judgements for the model.

The results of the study helped to formulate better policy guidelines for the marketing strategies of a local branch of an international computer company regarding its customers.

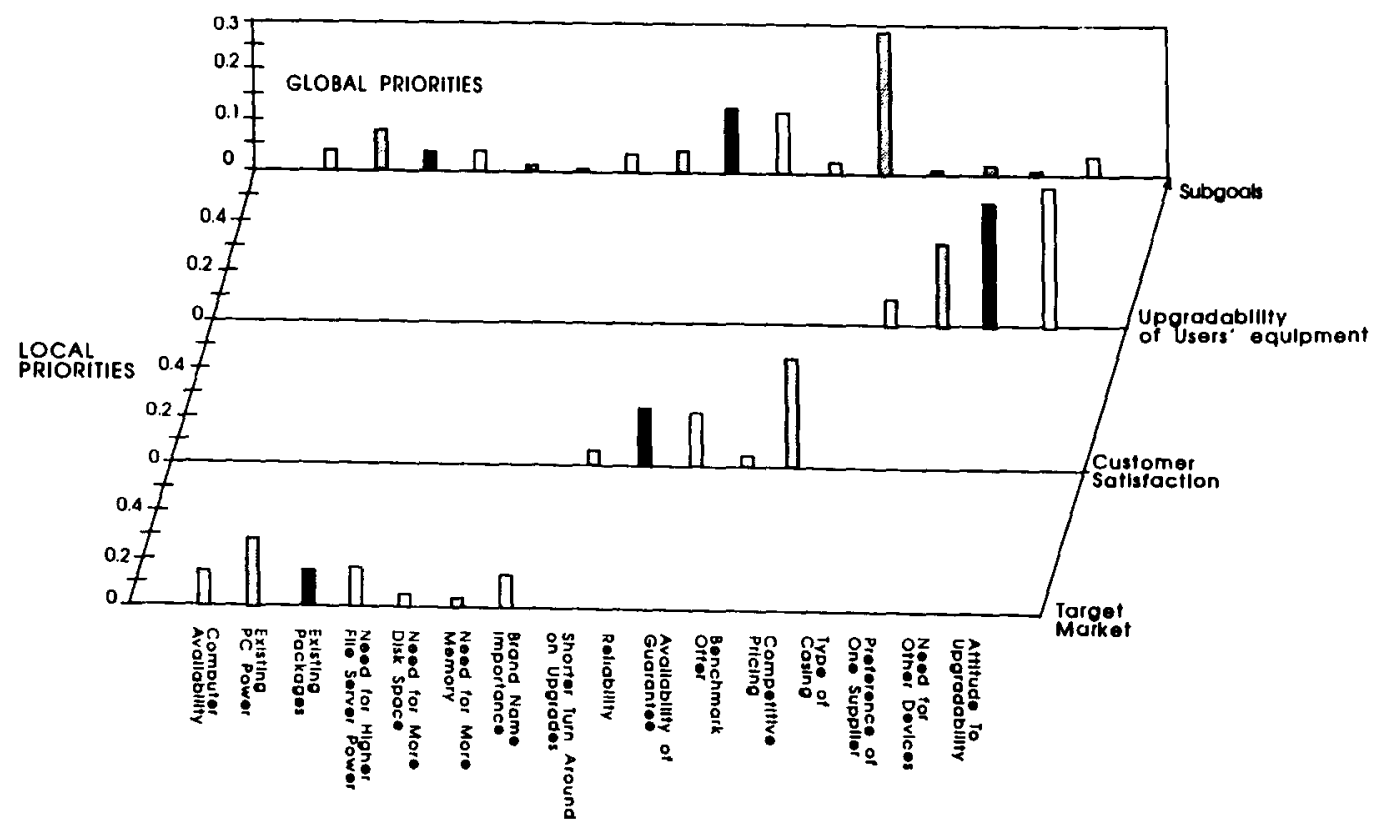
Figure 2 Local and global priorities of the factors in the Analyctic Hierarchy Model of factors affecting the upgradibility of personal
computers 
These policies were oriented towards continuous monitoring of the prices suggested by other dealers, improvement of the reliability of service to the customer, extending where possible the conditions of guarantees offered to the customer and establishing better working contact with the customer permitting thus in-depth knowledge of their existing PC power base, the types of software most widely used and the expected trends in their needs for new software and hardware. It is felt that the model which is presented above enables managers to gain a deeper insight about the relationships between the factors involved and can be instrumental in the provision of useful guidelines for increasing the effectiveness of marketing for PC upgrades.

\section{Conclusion}

An attempt was made to reveal the structure of the problem of prioritizing of factors affecting the upgradability of personal computers and the relationships between them. The multicriteria interpretation of the problem and the resulting priorities expressed through Figures 1 and 2 provide a foundation for better understanding of its nature and of the relationships within it. The suggested analytic hierarchy model and the derived priorities may serve as possible guidelines for the management of vendor companies in their attempt to find new ways of extending the life of these products as they move through the maturity stage of the product life cycle.

Notwithstanding the traditional criticisms levelled at difficulties encountered in the application of PLC theory, the model appears to provide a useful device for partially explaining new product development in the field of personal computing and the behaviour in competitive markets. Sales increases are obviously an important goal in the upgrading of PCs, but even more important is the consideration that profitability be maintained and ideally enhanced, as new product forms (extensions or improvements) are introduced. These, in turn, contribute to the flow of sales and profits and are eventually replaced by a succession of new, improved PC offerings.

The practical application of the results of the model suggest that the purpose of the research was satisfied and that top management is willing to trust results obtained through the Analytic Hierarchy Process. The proposed model is but one example illustrating how AHP permits them to structure their managerial problems in a better way. It helps to measure the influence of various factors affecting the marketing of upgrades for personal computers. On the basis of these measurements management can concentrate on the most important factors that are of critical nature. In the circumstances of the company where the authors applied this model these factors were competitive pricing, reliability of service provided by the dealer, availability of a guarantee offered to the customer and existing $\mathrm{PC}$ power in the customer base.

Through the use of a multicriteria decision-making approach based on the AHP this research attempts to go further than the one reported in Barnard \& Ehrenberg (1990), which applied single criteria techniques to a number of factors whose ranking is assumed to be the same. Thus the model discussed here attempts to reflect more closely a more realistic situation. While it is true that the use of multicriteria tech- niques in marketing research are generally gaining wider approval and applications, one can argue that the Analytic Hierarchy Process provides results that are more readily accepted by practising managers than those obtained using other techniques (Saaty, 1990). It is hoped that this study will provide a stimulus for further research oriented towards the validation of the structure of this model in other marketing decision areas and in particular its extension to cover factors affecting buyer behaviour in the mainframe and minicomputer industry, or in the study of individual computer brands.

\section{References}

Aaker, D. 1990. 'Brand extensions: the good, the bad, and the ugly', Sloan Management Review, 31(4): 47-56.

Barnard, N. \& Ehrenberg. A.S.C. 1990. 'Robust measures of consumer brand beliefs', Journal of Marketing Research, 27: 477484.

Boynton, A., Zmud, R. \& Jacobs, G. 1994. 'The influence of IT management practice on IT use in large organisations', MIS Quarterly, 18: 299-316.

Bretschneider, S. \& Wittmer, D. 1993. 'Organizational adoption of microcomputer technology: the role of sector', Information Systems Research, 4 (1): 88-108.

Buede, D. 1993. Aiding insight-survey, OR/MS Today, April: 52-60.

Dyer, R.F. \& Forman, E. 1991. An analytic approach to marketing decisions. Englewood Cliffs: Prentice Hall.

Gurbaxani, V. \& Mendelson, H. 1994. 'Modelling vs. forecasting: the case of information systems spending', Information Systems Research, 5(2): 180-190

Heide, J.B. \& Weiss, A.M. 1995. 'Vendor consideration and switching behavior for buyers in high technology markets', Journal of Marketing, 59(7): 30-43.

Karmarkar, U.S. 1996. 'Integrative research in marketing and operations management', Journal of Marketing Research, Vol. XXXIII: 125-133.

King, J.L., Gurbaxani, V., Kraemer, K., McFarlan, F.W., Raman, K.S. \& Yap, C.S. 'Institutional factors in information technology innovation', Information Systems Research, 5(2): 139-169.

Kotler, P. 1988. Marketing management analysis, planning, implementation and control. 6th ed. Englewood Cliffs: Prentice Hall.

Lambkin, M. \& Day, G.S. 1989. 'Evolutionary processes in competitive markets: beyond the product life cycle', Journal of Marketing, 53(3): 4-20.

Naudé, P. \& Lockett, G. 1993. 'Market analysis via judgemental modelling an application in the UK chemical industry', European Journal of Marketing, 27(3): 5-22.

Rosenthal, S.R. \& Salzman, H. 1990. 'Hard choices about software: the pitfalls of procurement', Sloan Management Review, 31(4): 81-91.

Rosenzweig P.M. 1994. 'When can management science research be generalized internationally?', Management Science, 40(1): 28-39.

Saaty, T.L. 1990. Multicriteria decision making - the analytic hierarchy process. 2nd ed. Pittsburgh: RWS Publications.

Saaty, T.L. 1994. Fundamentals of multicriteria decision making with the analytic hierarchy process. Pittsburgh: RWS Publications

Schoemaker, P.J. \& Waid, C.C. 1982. 'An experimental comparison of different approaches to determining weights in additive utility models', Management Science, 28(2): 182-196.

Seymour, J. 1992. 'Upgradable PCs', PC Magazine, December 8: $110-112$.

Sridhar Moorthy, K. \& Png, I.P.L. 1992. 'Market segmentation, cannibalization and the timing of product introductions', Management Science, 38(3): 345-359. 
Sullivan, M. 1992. 'Brand extensions: when to use them', Management Science, 38(6): 793-806.

Wind, Y. \& Saaty, T. 1980. 'Marketing applications of the analytic hierarchy process', Management Science, 26(7): 641-657.

Appendix: some introductory remarks on the analytic hierarchy process

A very brief description of some basic facts and steps in the application of the Analytic Hierarchy Process (AHP) as a method for dealing with complex multicriteria decision problems can be presented as:

A. Definition of the problem in the form of a hierarchy whose higher levels reflect the management objectives and the lower levels reflect the factors influencing them (e.g. see Figure 1).

B. Create matrices containing the pairwise comparisons between each two elements of a given level of the hierarchy towards their contribution or influence over a factor from a higher level that is related to them. For this purpose a nine-point ratio scale is used. It was found by Saaty to give the most satisfactory results (1990).

The information displayed in such a matrix is interpreted as follows: every element, $a_{j 1}$, of the matrix A shows the relative contribution to the subject of comparison of the $i$ th activity as compared to the $j$ th activity, i.e. $a_{i j}=w_{i} / w_{i} \quad 1<i<n, \quad 1<j<\quad n$

Note that:

Aw $=n w \quad$ where $w=\left[w_{1}, w_{2}, \ldots w_{3}\right]$

The vector of priorities, $w$, is obtained from equation (2) and is simply given as the normalized eigenvector of the matrix A corresponding to its largest eigenvalue $\mathrm{L}_{\max }>=$ $n$. These are local priorities, reflecting the importance of the elements within a cluster with respect to its root. Saaty has defined a consistency ratio which when greater than 0.1 identifies matrices where revision of judgement is necessary (1990).

C. When more than one level is involved, hierarchical composition is used to weight the eigenvector by the weights of the criteria and the sum is taken over all weighted eigenvector entries corresponding to those in the lower level and so on, resulting in a global priority vector for the lowest level of the hierarchy. The global priorities express the importance of each element with respect to the overall goal of the Analytic Hierarchy Model. For more information on the AHP see Saaty (1990).

The above procedures were incorporated in a prototype version of a software package developed by one of the authors. It is possible to use also other commercial products like Expert Choice or HIPRE. For more information on some software implementations of AHP see Buede (1993). 